\title{
REPRESENTAÇÃO CORPORAL ENTRE JOVENS UNIVERSITÁRIOS: BELEZA, SAÚDE E INSATISFAÇÃO NA VIVÊNCIA DE UM CORPO-VITRINE
}

\author{
BODY REPRESENTATION AMONG YOUNG UNIVERSITY STUDENTS: BEAUTY, \\ HEALTH AND DISSATISFACTION IN THE EXPERIENCE OF A BODY-SHOWCASE
}

\section{Raquel Ferreira Miranda ${ }^{1}$, Tais Silva Almeida ${ }^{2}$, Tatiana Coura Oliveira ${ }^{3}$, Caliane Santos Souza ${ }^{4}$, Monise Viana Abranches ${ }^{5}$}

'Autora para correspondência. Doutora em Psicologia. Docente na Universidade Federal de Viçosa.
Rio Paranaíba, Minas Gerais, Brasil. raquelmirandaufv@gmail.com
2Nutricionista pela Universidade Federal de Viçosa. Rio Paranaíba, Minas Gerais, Brasil.t tais.almeida@ufv.br
${ }^{3}$ Doutora em Epidemiologia. Docente na Universidade Federal de Viçosa. Rio Paranaíba, Minas Gerais, Brasil. contato.tatiana@gmail.com
${ }^{4}$ Graduanda em Nutrição na Universidade Federal de Viçosa. Rio Paranaíba, Minas Gerais, Brasil. calissouza@hotmail.com
${ }^{5}$ Doutora em Biologia Celular e Estrutural. Docente na Universidade Federal de Viçosa. Rio Paranaíba, Minas Gerais, Brasil.
monisevianaufv@hotmail.com

RESUMO I O corpo, na contemporaneidade, assume posição de centralidade na vida humana atuando como mediador nas relações sociais, impactando na aceitação dos sujeitos por outros indivíduos que compartilham o mesmo meio social. Este estudo buscou compreender as vivências relatadas por estudantes universitários advindas das representações do corpo focando, especialmente, na percepção da autoimagem corporal e nos sentidos atribuídos ao corpo. Participaram deste estudo 22 indivíduos com idade entre 18 a 27 anos. A análise dos dados foi feita utilizando-se a técnica de análise de conteúdo, segundo Bardin. Os resultados indicaram a percepção do corpo como um objeto de investimento, sendo este feito por meio do controle dietético e da atividade física visando à adequação aos padrões corporais culturalmente valorizados.

Palavras-chave: corpo; autoimagem corporal; insatisfação corporal.

\begin{abstract}
The body, in the contemporaneity, assumes a central position in human life acting as mediator in social relations, impacting on the acceptance of the subjects by other individuals who share the same social environment. This study sought to understand the experiences reported by university students coming from the representations of the body focusing, especially, on the perception of body self-image and the meanings attributed to the body. Twenty-two individuals aged 18 to 27 years participated in this study. The analysis of the data was done using the technique of content analysis, according to Bardin. The results indicated the perception of the body as an investment object, which is done through dietary control and physical activity aiming at the adaptation to culturally valued body patterns.
\end{abstract}

Keywords: body; body self-image; body dissatisfaction. 


\section{INTRODUÇÃO}

A crescente preocupação com o corpo em nossa sociedade é consequência de um conjunto de transformações característicos do tempo em que vivemos. Dentro do processo de desestruturação dos contextos sociais tradicionais, característico da modernidade tardia, as práticas que se ligam ao corpo são agora reflexivamente mobilizadas (Beck, Giddens, \& Lash, 1997). Beleza e aceitação social passaram a ser dimensões de grande influência na vida cotidiana que se conectam também ao projeto contemporâneo de autoidentidade, hábitos de vida e à aparência corporal (Giddens, 2002). A pressão social contemporânea que valoriza a magreza como ideal estético, bem como a saúde tem se transformado, nos últimos anos, em um padrão que envolve magreza e definição muscular (Kelley, Neufeld, \& Musher-Eizenman, 2010).

O corpo, na contemporaneidade, assume posição de centralidade na vida humana atuando como mediador nas relações sociais, impactando na aceitação dos sujeitos por outros indivíduos que compartilham o mesmo meio social. De acordo com Giddens (2002), na modernidade tardia, o corpo adquire status de moeda de troca em um contexto marcado por intolerância a qualquer desvio nos padrões estéticos compartilhados socialmente. A reflexividade do eu se estende ao corpo e marca a perspectiva de que somos o que fazemos de nós mesmos, tornando o corpo cada vez mais socializado, imerso nas interações da vida cotidiana por meio da aparência corporal e da postura, que refletem o modo como o corpo é mobilizado em relação às convenções cotidianas.

Nas últimas décadas, influenciados por fatores socioculturais, indivíduos de ambos os gêneros têm sido afetados pela pressão associada a um determinado padrão de imagem corporal idealizado. Em relação às mulheres, a literatura faz referência ao corpo magro como sinônimo de beleza, enquanto o padrão estético masculino está mais associado à definição corporal, especialmente, músculos e força (Ribeiro \& Ribeiro, 2003; Lopes, Baldasso, Sousa, Chaud, \& Camargo, 2012; Damasceno, Vianna, Vianna, Lacio, Lima \& Novaes, 2006). Há indícios de que esta situação interfira na percepção da imagem corporal (Neighborsa, \&
Sobalb, 2007; Tessmer, Silva, Pinho, Gazalle, Fassa, 2006).

A imagem corporal é um aspecto central no desenvolvimento psicológico e interpessoal (Alves, Pinto, Alves, Mota, \& Leirós, 2009). Ribeiro e Tavares (2011), em uma revisão dos trabalhos de Seymour Fisher, ressaltam a perspectiva da organização multidimensional da imagem corporal. McKay, Mikosza e Hutchins (2005) apresentam a imagem corporal como uma imagem psíquica construída a partir de um corpo físico, por meio da apropriação de significados simbólicos, construídos socialmente e em contínua transformação. Uma imagem corporal positiva reflete em uma melhor qualidade das relações interpessoais, maior segurança em relação ao corpo, e uma percepção melhor sobre a própria personalidade (Barbosa, 2011).

A percepção que $\circ$ indivíduo tem de si próprio impacta em seus relacionamentos interpessoais, sua saúde, autoestima e bem estar. Assim, uma avaliação negativa da própria imagem pode propiciar repercussões psíquicas acarretando distúrbios como a anorexia e bulimia (Fernandes, 2007; Alves, Pinto, Alves, Mota, \& Leirós, 2009; Secchi, Camargo, \& Bertoldo, 2009; Rech, Araujo, \& Vanat, 2010).

Uma série de atributos negativos associados à gordura corporal estabeleceu, nos dias atuais, um quadro de lipofobia ampliando quadros de sofrimento e insatisfação corporal (Barros, 2001; Novaes \& Vilhena, 2003). A aversão à gordura corporal mescla sentidos de ausência de saúde, uma vez o excesso de peso tem sido apontado como fator de risco para doenças crônico-degenertivas, a um valor estético negativo. Atribuir feiúra ao outro ou perceber-se feio, num cenário de lipofobia é revelador das profundas mudanças sociais que marcam a forma de lidar com o corpo (Novaes et al., 2003) pautada em normas, valores e padrões da sociedade de consumo em que o indivíduo está inserido (Camargo, Goetz, Bousfield, \& Justo, 2011). A definição do que é belo ou feio gira em torno de conceitos como totalidade, organicidade, unidade, integridade a partir de uma construção cultural baseada na valorização de certos traços tidos como esteticamente aprazíveis ou não, construídos dentro de sistemas de representação (Kirchof, \& Bonin, 2013). 
Esta situação se dá num momento onde os índices de sobrepeso e obesidade da população adulta brasileira somados são de quase $60 \%$ (IBGE, 2105). Com o aumento nesses índices, evidenciase mais acentuadamente a insatisfação corporal dos indivíduos com o próprio corpo, propiciando a busca do corpo "perfeito" por meio de práticas pouco salubres tais como dietas extremamente restritivas, atividade física muito intensa, abuso de medicamentos diuréticos, laxativos, anorexígenos ou daqueles que promovem ganho de massa muscular como os hormônios, para além de intervenções cirúrgicas de natureza estética, dentre outros métodos estéticos (Swinburn et al., 2011 ). A integração entre percepção corporal, vivências advindas destas experiências e influências do contexto sociocultural são a base para uma compreensão mais ampla deste fenômeno.

O corpo tem se tornado um objeto de investimento que precisa ser melhorado, ampliado, ajustado para se adequar aos padrões culturalmente valorizados, em uma perspectiva que coloca o sujeito como responsável por sua aparência física. Dantas (2011) sinaliza que a busca pela boa forma associada à busca da saúde é falsa, visto que na busca pela saúde há um ponto em que se identifica ter obtido sucesso, entretanto na incansável busca pela boa forma não se encontra este ponto, há sempre algo mais a ser modelado para se atingir o corpo perfeito.

Goldenberg (2006) ao abordar o corpo como 'capital' apresenta que hoje o corpo está sujeito à vigilância constante, à busca da perfeição e à submissão aos padrões de beleza, que agora pode ser conquistada ou até mesmo comprada. Desse modo, o corpo, fruto da cultura vigente, está também vinculado à ideia de consumo fazendo parte de uma cadeia de interesses que vende 'saúde' através de aparelhos de ginástica, suplementos, anabolizantes, cirurgias pláticas, fármacos. Neste cenário os meios de comunicação de massa produzem anúncios publicitários pautados em corpos perfeitos, em geral com uso da edição gráfica do software Photoshop, que possibilita a construção de belos corpos que vendem produtos perfeitos e assim contribuem e incentivam a batalha pelo belo.
É neste ambiente sociocultural que a idealização do corpo fomenta o desenvolvimento de distorções da imagem corporal, pois perpassa o aumento concreto dos indicadores de sobrepeso, sem uma reflexão crítica da situação, sendo cada vez mais evidente a insatisfação corporal para ambos os sexos (Ribeiro et al., 2003; Lopes et al., 2012). De acordo com estudo de Almeida, Santos, Passian e Loureiro (2005) a insatisfação com o corpo tem sido frequentemente associada à discrepância entre a percepção e o desejo relativo a um tamanho e a uma forma corporal.

Em um estudo com 535 estudantes universitários Miranda, Filgueiras, Neves, Teixeira, Ferreira (2012) sinalizam que indivíduos jovens parecem ser mais vulneráveis às situações de insatisfação corporal. Os participantes das áreas da saúde e humanas se mostraram mais insatisfeitos em relação ao corpo quando comparados com estudantes da área exatas, os autores sugerem que essa diferença pode estar relacionada ao fato dos primeiros estarem vinculados à área do conhecimento que tem como foco de estudo o corpo humano. As mulheres em sobreposição aos homens apresentaram um maior índice de insatisfação corporal e, principalmente, indivíduos de ambos sexos com sobrepeso e obesidade.

A similaridade apresentada entre saúde e beleza, no discurso midiático, pode acarretar repercussões nas representações e vivências dos indivíduos (Van Den Berg, Paxton, Keery, Wall, Guo, \& NeumarkSztainer, 2007; Dalleya, Buunka, \& Umitc, 2009). Tal situação é amplificada diante da proliferação de programas de TV, livros, revistas, blogs que abordam temáticas relativas à estética corporal associada à saúde, sendo fundamental compreender as vivências, as experiências subjetivas associadas ao corpo e à construção da imagem corporal de jovens. Isto porque as diversidades socioculturais e as mudanças tecnológicas alteraram o acesso à informação e propiciaram repercussões subjetivas, individuais ou coletivas que devem ser compreendidas. Este trabalho objetivou compreender a percepção da autoimagem corporal, os sentidos atribuídos ao corpo e as vivências advindas destas representações em jovens estudantes universitários. 


\section{METODOLOGIA}

As razões para utilização da pesquisa qualitativa estão relacionadas à natureza do problema estudado e às questões e objetivos que orientaram a investigação. De acordo com a perspectiva de Minayo (1998) a investigação social deve contemplar o aspecto qualitativo, considerando que - sujeito de estudo está em determinada condição social, pertencente a determinado grupo social com suas crenças, valores e significados.

Desse modo deve-se observar que o objeto de estudo das ciências sociais é complexo e em permanente transformação ao trabalhar com - universo de significados, motivos, aspirações, crenças, valores e atitudes o que corresponde a um espaço mais profundo de processos que não podem ser reduzidos à operacionalização de variáveis (Minayo, 1996, 1998).

Ludke e André (1986) salientam que a pesquisa qualitativa tem cinco características básicas, sendo elas: o fato de ter o ambiente natural como fonte direta de dados e o pesquisador como seu principal instrumento; os dados coletados são predominantemente descritivos; a preocupação com o processo é maior do que com o produto; - "significado" que as pessoas dão às coisas e à vida são os focos de atenção e a análise dos dados tende a seguir um processo indutivo.

Optou-se pela realização de entrevista semiestruturada com jovens estudantes universitários como estratégia metodológica. A entrevista é considerada, por Ludke e André (1986), como um dos instrumentos básicos para a coleta de dados. As autoras ressaltam o caráter de interação que permeia a entrevista, havendo uma atmosfera de influência recíproca entre quem pergunta e quem responde assim como há uma captação imediata e corrente da informação desejada. Corroborando com essa perspectiva Festinger e Katz (1974) sinalizam que as percepções, atitudes e opiniões não podem ser inferidas pela observação, mas são acessíveis por meio da entrevista. Para estes autores uma ótima comunicação ocorre se o entrevistado percebe $\circ$ entrevistador como alguém capaz de compreender e aceitar sua situação básica.
O relacionamento ideal entrevistador-entrevistado é aquele no qual existe um considerável grau de intimidade em termos de compreensão e aceitação, mas é mantida a imparcialidade ou objetividade de um relacionamento do tipo profissional-cliente. Neste sentido, tem-se na investigação qualitativa uma importante questão: a subjetividade do pesquisador (Godoy, 1995). Machado (2002) ressalta a necessidade de se observar a implicação do pesquisador com seu objeto de pesquisa e - lugar que o pesquisador ocupa em relação ao entrevistado. A partir destas perspectivas é importante esclarecer que as pesquisadoras que atuaram na coleta de dados também eram jovens universitárias, portanto possuíam uma relação de simetria com os sujeitos da pesquisa, embora não estabelecessem, necessariamente, uma relação de amizade com os pesquisados.

A pesquisa foi fruto de discussões ocorridas no Núcleo de Estudos em Relacionamento Interpessoal, Saúde e Sociedade (NERISS), grupo instituído na Universidade Federal de Viçosa campus de Rio Paranaíba, Brasil. O estudo foi desenvolvido por meio de 22 entrevistas com jovens estudantes universitários. A amostra que subsidiou o estudo foi fechada de acordo com a saturação teórica, ou seja, interrompeu-se a coleta de dados quando se verificou que a interação entre campo de pesquisa e $\circ$ investigador não mais fornecia elementos para balizar ou aprofundar a teorização. A saturação teórica foi constatada em função dos dados apresentarem certa repetição indicando - escasseamento de novos tipos de enunciados (Fontanella, Luchesi, Saidel, Ricas, Turato, \& Melo 2011 ; Fontanela, Ricas, \& Turato, 2008).

As entrevistas ocorreram entre os meses de agosto e setembro de 2016, na residência dos participantes visando criar um ambiente amistoso e propício à exposição das vivências dos participantes em relação ao próprio corpo.

Inicialmente foram coletados dados relativos ao perfil dos entrevistados, abordando aspectos sociodemográficos e solicitando peso e altura autorrelatados para a realização do cálculo do Índice de Massa Corporal (IMC=kg/m2). O IMC referido foi incluído para que pudesse ser considerada informações referentes à situação de 
eutrofia (IMC $\geq 18,5 \leq 24,99 \mathrm{~kg} / \mathrm{m} 2$ ), sobrepeso (IMC > $25 \leq 29,99 \mathrm{~kg} / \mathrm{m} 2$ ) ou obesidade (IMC $\geq 30 \mathrm{~kg} / \mathrm{m} 2$ ) (WHO, 1995). Entretanto, na análise dos dados estas medidas não foram consideradas de modo classificatório, mas apenas como um fator de comparação entre as medidas referidas pelo participante e a percepção da imagem corporal. Isto porque estudos demonstram que pode haver uma falsa representação de características corporais, como altura e peso autorrelatados (Betz, Mintz, \& Speakmon, 1994; Wada, Tamakoshi, Tsunekawa, Otsuka, Zhang, Murata, \& Toyoshima, 2005).

Os relatos foram gravados e transcritos pelas pesquisadoras sendo, em seguida, armazenadas em local seguro, sob responsabilidade do pesquisador principal. $O$ estudo atendeu às determinações das questões éticas em pesquisa (BRASIL, 1996), tendo sido aprovado pelo Comitê de Ética em Pesquisa da Universidade Federal de Viçosa conforme parecer número 1.359 .583 Os participantes foram informados a respeito dos procedimentos de pesquisa e assinaram o Termo de Consentimento Livre e Esclarecido (TCLE).

A análise dos dados obtidos com os instrumentos de coleta de dados adequados ao atingimento dos objetivos propostos foi feita mediante análise de conteúdo, segundo Bardin (2003). O interesse não reside na descrição dos conteúdos, mas no que estes poderão nos ensinar após serem tratados. Portanto, a intenção da análise de conteúdo é a inferência de conhecimentos relativos às condições de produção ou de recepção, inferência esta que recorre a indicadores. Dessa maneira, ao iniciar o trabalho de análise de conteúdo deve-se realizar uma leitura flutuante do material com o objetivo de destacar os aspectos relevantes e pertinentes ao estudo. $O$ tratamento do material consiste em: ordenação; classificação e análise propriamente dita, surgindo assim, categorias de análise (Bardin, 2003).

\section{RESULTADOS E DISCUSSÃO}

grupo de pesquisa foi composto por 22 jovens estudantes universitários, sendo dezesseis do sexo feminino e seis do sexo masculino. A idade variou entre 18 e 27 anos, sendo 17 participantes com idade entre 18 e 23 anos. Os participantes serão identificados pela letra $E$, pelos números de 1 a 22 e em seguida o sexo, sendo feminino(F) e masculino(M), por exemplo: (E1-F). De acordo com dados do IMC autorrelatado três participantes apresentaram sobrepeso (E6-F; E9-F; E3-M) e um obesidade (E1 2-F).

O eixo orientador da análise dos dados foi compreender a percepção da autoimagem corporal e as representações que os participantes apresentaram do corpo privilegiando as vivências relatadas.

A representação do corpo, entre os participantes, apresenta-se relacionada às categorias: academia/ definição muscular, estética/aparência retratadas na perspectiva de beleza e feiura e alimentação saudável/dieta, todas com um viés pautado no discurso da saúde.

Entre os participantes masculinos emergem das narrativas, primordialmente, referências ao exercício físico e desenvolvimento da musculatura, enquanto entre as participantes femininas emergem dieta $e$ aspectos estéticos como cintura fina, ausência de estria e celulite: "Dieta, sarada e academia."(E16-F); "Tanquinho, definição e músculo."(E1 1-M). O corpo magro também encontra espaço no discurso feminino, sendo associado à sensação de bem estar: "Gosto do meu corpo de manhã né, que a gente se sente mais magra..."(E15-F); "Quando passa o período menstrual que já desinchei que estou mais magra, geralmente eu me sinto melhor."(E9-F)

A dicotomia corpo belo/corpo feio também embasa as representações do corpo entre os participantes. Kirchof e Bonin (2013) sinalizam que um corpo belo é aquele que se aproxima, da forma mais exata possível, de uma forma pré-definida como ideal. Para os participantes, este corpo ideal e, portanto, belo, apresenta uma multiplicidade de sentidos que abarcam especialmente a transição de um valor estético do corpo para uma perspectiva da saúde. Daí - corpo magro, delineado, modelado pela ausência de gordura, a estética e a vaidade com o corpo são associadas ao autocuidado, ao condicionamento físico, ao bom humor e autoestima elevada aspectos apresentados no discurso contemporâneo como característicos de uma vida saudável. 
Chama a atenção o aparecimento de atributos que não são, em sua origem, associados diretamente ao corpo como bom humor e/ou autoestima, mas que estão relacionados à satisfação que $\circ$ corpo belo 'idealizado' promove. Neste sentido a vivência corporal pauta-se em uma corporeidade entendida como um espaço social, significado a partir de elementos sócio-históricos e culturais que dão sentidos e inteligibilidade ao corpo (Beiras, Lodetti, Cabral, Toneli \& Raimundo, 2007).

Em estudo de Fontes, Borelli e Casotti (2012) poucas foram as práticas de beleza identificadas como permitidas para $\circ$ gênero masculino. Em geral, a preocupação com atratividade física é considerada um elemento central da feminilidade, bem como o consumo de práticas de beleza. Neste estudo, os participantes masculinos apresentaram-se atentos ao discurso da beleza, mas esta foi associada a estratégias voltadas para o corpo saudável, pautadas no discurso da saúde como "um corpo belo é ter saúde, praticar exercício e ter uma alimentação saudável" (E13-M).

A beleza é retratada, pelas participantes femininas, essencialmente, por meio do corpo delineado pelo trabalho de musculação e baixo índice de gordura corporal, ausência de marcas na pele: "Corpo sarado, uma pele sem espinha também é beleza, e não sei umas pernas torneadas, é bom né...(risos)"(E6-F) e o corpo magro aparece como referencial de beleza da participante que apresenta sobrepeso "Magreza, cintura fina e não ter celulite." (E9-F).

A feiura é representada pelo excesso de peso ou, especificamente, gordura corporal, e pela magreza, sendo também retratada como falta de cuidado consigo mesmo. Porém, além de aspectos associados à aparência física uma série de características como baixa autoestima, mal humor, ignorância, soberba e maldade são associadas à feiura: "Magreza, baixa autoestima, um mau cuidado" (E4-M); "Sobrepeso, excesso de barriga e perna." (E6-F); "Gordo, magreza demais, e falta de simpatia." (E13-M).

O feio se apresenta nas narrativas como disforme e desproporcional, sua manifestação não se limita à aparência física, estando associada à degradação moral. Essas representações estão compatíveis com as personagens bruxas dos contos de fada tradicionais, que apresentam características de deformidade corporal associadas à maldade, crueldade (Kirchof, \& Bonin, 2013).

Uma participante expressa quão angustiante a feiura pode ser ao associá-la ao corpo gordo, retratando implicações físicas e psíquicas como a falta de ar e sentimentos de tristeza: "Feiura parece que tipo... esmaga o pescoço, eu sinto falta de ar, tristeza, depressão. É porque às vezes a feiura, (...) tem uma pessoa feia eu me sinto mal, talvez do que a pessoa possa sentir, que nem eu tô com um corpo agora bem gordinho, eu sinto às vezes por ele tá gordo, eu associo com feiura, e feiura falta de ar, parece que sinto o pescoço sendo esmagado." (E12-F). O feio, mais do que indiferença, gera rejeição e desconforto (Feitosa, 2004).

Alimentação e atividade física são dimensões relacionadas aos cuidados corporais entre os entrevistados. Há uma idealização destas dimensões o que parece dificultar, para a metade dos participantes, a percepção de cumprimento dos padrões considerados saudáveis: "(...) sempre tento emagrecer, mas eu começo (dieta) e tipo, não dou sequência."(E1 2-F); "Eu não consegui seguir dieta, não. Foi meio desastroso. Não tinha refeições, eu me restringia de comer." (E2 1-F)

A satisfação com o corpo é retratada à medida que avaliam estarem obtendo sucesso na dieta, na realização contínua do exercício físico e em momentos que se sentem mais magros, portanto a satisfação é associada à perspectiva de um corpo mais magro e à realização das atividades consideradas como saudáveis: "Fico feliz com meu corpo quando consigo praticar esporte e alimentação regrada."(E2-M); "Assim geralmente quando eu faço dieta, que começo a entrar no ritmo eu gosto."(E6-F)

Todos os participantes retratam alguma área corporal a ser alterada ou algum hábito relativo à alimentação ou atividade física ainda a ser desenvolvido para que estejam plenamente satisfeitos pautados na adequação aos padrões vigentes, especialmente atendendo ao discurso da saúde: "...queria fazer atividade física, não para emagrecer, mas sim para saúde." (E20-F) 
A insatisfação com o corpo é considerada como um fenômeno natural, e até mesmo constituinte do gênero feminino: "Tem dias que não to satisfeita, mas no fundo eu sei que tô bem, mas é da mulher."(E5-F). A idealização do corpo tem repercussões que vão além do físico, impactam na vida psíquica abrangendo o âmbito das relações interpessoais. Isto porque o corpo é importante objeto na interação entre as pessoas e na dinâmica das relações sociais, deste modo, o corpo fora do padrão, apresenta-se hierarquicamente inferior acarretando sofrimento. À medida que o padrão corporal estabelecido é amplificado, indo além das formas físicas, abarcando aspectos comportamentais e embasado no discurso da saúde estabelece-se uma polifonia, uma polissemia que parecem desencadear a percepção de inadequação e a vivência da insatisfação corporal. "Não, nem um pouco satisfeita. Sou alta, gordinha, e sou um pouco desproporcional, eu acho. Em cima muita coisa, embaixo nada. Então eu acho meu corpo desproporcional." (E21-F)

A escolha das roupas está associada ao desejo de mostrar ou esconder o corpo, e ocorre em função dos padrões socialmente compartilhados: 'isto tal corpo pode, aquilo não pode', acarretando vivências restritivas e de inadequação social: "Eu gosto de jeans, mas eu não posso usar, eu gosto de vestido, gostaria muito de usar uma calça jeans." (E1 2-F); "Uso blusa maior que não mostra a barriga nem nada."(E15-F); "Uso roupa preta porque emagrece. Tinha uma época que era mais magra, então eu não me importava com isso não. Usava a roupa que dava vontade."; (E21-F) "Quando você é gordinho você quer uma peça pede pra olhar e não entra em você, aí fica chato."(E6-F).

Strahan, Wilson, Cressman e Buote (2006) apontam para 0 importante papel das normas culturais para aparência na determinação do processo de comparação social e autoavaliação, assim, padrões irreais de beleza podem contribuir para a insatisfação com $\circ$ corpo. Os participantes apresentaram um discurso referenciado por um corpo denominado por eles como ideal e ao indicarem a parte do corpo que mais valorizam citaram rosto, cabelo, pescoço. Cabe ressaltar que são áreas corporais que estão supostamente mais protegidas da gordura e por isto imune aos padrões idealizados de beleza: "Gosto mais do peito e do pescoço, digamos que é a parte mais magra."(E3-M); "Rosto." (E1-F); "Minha boca." (E6F); "Meus olhos e cabelos."(E1 2-F).

Vivências de inadequação e de restrição retratadas pelos participantes remontam momentos onde o corpo "fora" dos padrões socialmente valorizados aparece como ator principal de situações constrangedoras que causam sofrimento e corroboram para a insatisfação corporal: "Já fui muitas vezes motivo de piada, bullying, atualmente não, mas quando era acima do peso sim."(E2-M); "Ah... já passei por muitas situações desagradáveis, por exemplo, de não poder comprar uma roupa, isso é desagradável pra mim, entrar dentro de um ônibus, de um carro, às vezes vou pedir carona com os colegas eu me sinto mal, porque eu sei que vou apertada, isso me estrangula sabe, isso me faz mal, muitas vezes de entrar dentro do ônibus, e sentir que as pessoas estão rindo de mim, rindo do meu corpo, uma vez entrei dentro de um carro e na hora de sair, não tava conseguindo sair, tipo não era carro de 4 portas então não conseguia sair." (E12-F). Apesar da maior parte das experiências retratarem constrangimentos em função do sobrepeso ou obesidade, a magreza, ao ser considerada fora dos padrões socialmente valorizados também propicia sofrimento: "Teve uma época na minha adolescência que era muito magra, me sentia constrangida, e sofria bulling."(E1 4-F)

Na avaliação da insatisfação corporal a teoria da comparação social proposta por Festinger tem sido utilizada (Strahan, Wilson, Cressman, \& Buote, 2006; Van Den Berg \& Thompson, 2007; Bailey \& Ricciardelli, 2010) indicando que para formar avaliações de si mesmos, os indivíduos se comparam a outros em seu ambiente social considerando características que são importantes para eles por serem valorizadas no meio social em que estão inseridos. Estudos de comparação de aparência geralmente encontraram suporte para o importante papel da comparação social de aparência na insatisfação corporal (Van Den Berg \& Thompson, 2007). Apesar de não ter sido proposto comparações entre o entrevistado e outros indivíduos, algumas narrativas evidenciaram comparações com o próprio corpo em diferentes momentos da vida influenciando a percepção corporal. 
Ao serem incitados a se autodescreverem para um desconhecido em situação de interação 'on line', ou seja, sem o risco do encontro presencial, quinze participantes citaram $\circ$ uso de características que não são físicas como modo de se apresentarem afirmando não ser necessário descreverem o corpo, indicaram o uso de outras características: "Coisas que representa eu mesma, eu gosto muito de cozinhar, de estudar, eu acho legal mencionar isso que eu gosto, eu não vejo necessidade de descrever meu corpo." (E9-F); "Falaria que sou um cara que gosta de conversar, que gosta de sair, gosta de conhecer pessoas novas, debater idéias, do meu corpo eu não falaria nada." (E13-M); "Simpática, sorridente, eu acho que é isso, não entraria com detalhes do meu corpo." (E15-F). E quando o corpo foi abordado as características corporais foram apresentadas de modo dúbio, desvalorizando o corpo não apenas pela adjetivação 'mais ou menos', mas pelo próprio uso da palavra corpo no diminutivo: "Eu não poderia mentir, né?! Então, estatura mediana, não sou magra e nem gorda, tem um corpinho mais ou menos. Só isso." (E18-F)

A evitação da descrição corporal pode estar relacionada à categoria engano corporal que, segundo Hildebrandt, Shiovitz, Alfano e Greif (2008), se refere à deturpação intencional de informações pessoais sobre a aparência, tamanho do corpo ou composição corporal para outras pessoas. Os autores relatam que há uma série de comportamentos e atividades envolvidas na distorção do corpo aos olhos dos outros que não são limitados à autorrevelação sobre a forma, o peso, mas disfarces de aspectos naturais de sua aparência por meio do uso de maquiagem, bronzeamento ou mesmo cirurgia plástica e comparações sociais.

Considerando que comentários, sobre a aparência física de um indivíduo, são uma importante fonte influência sociocultural (Bailey \& Ricciardelli, 2010) este estudo buscou identificar 0 modo pelo qual os participantes relatavam serem percebidos por pessoas significativas como familiares, namorado(a) e amigos. É interessante observar que diferentemente das características elencadas durante o autorrelato, foram muito abordados aspectos relativos ao corpo apresentar-se magro ou gordo: "lam falar que tô magro, que tô emagrecendo." (E13-M); "Minha família já vai falar que eu engordei, já notou a diferença." (E 1 1-F); "A minha família, me acha magra, alta e magra, ...mas eu não concordo com eles." (E21-F). Parece que nas relações íntimas dos participantes a forma corporal e, especialmente 0 peso corporal são objeto importante ou temática frequente nos relacionamentos. A partir do momento que a forma e o peso corporal tornaram-se centrais na constituição dos indivíduos contemporâneos e, a partir daí objetos de julgamento, de idealização eles passaram a fazer parte da esfera íntima da vida porque dão forma material a uma narrativa particular da autoidentidade.

Mesmo que pelo olhar dos familiares os participantes relatem um corpo magro muitos têm dificuldade em se perceberem com o corpo adequado, bonito e estarem satisfeitos com o próprio corpo: "Acho por ser familiares querem agradar, sempre me dizem que sou bem magrinho, embora eu não me ache." (E3-M); "Acho que acham que tenho formato de corpo bonito, mas não acho assim." (El4-F). Na contemporaneidade a relação do indivíduo com o corpo é permeada pela insatisfação, visto que sempre há o que aprimorar, entretanto esta abertura ao aprimoramento está associada ao sofrimento pela insatisfação com o corpo, pela vivência de imperfeição e menos valia.

As práticas de controle de peso e de modelagem corporal, abordadas pelos participantes, foram primordialmente a dieta e o exercício físico. Porém, houve relatos de uso de medicamentos seja para emagrecer, seja para ganho de massa muscular ou engordar e dois relatos de intervenção cirúrgica: "Quando eu era mais novo eu tinha peitinhos... (risos) Fiz uma cirurgia plástica, é uma cirurgia que poderia ser feita sem cirurgia plástica, mas achei melhor fazer com um cirurgião plástico por causa da aparência." (E13-M); "O médico já passou um antidepressivo na primeira consulta, porque tava chorando muito(...) era um remédio que fazia perder peso, e muitas vezes já procurei, outras pessoas que tinham remédio e me passavam sabe, já tentei de todo jeito, usei um rémedio 2,3 dias que eu quase morri." (E1 2-F)

Strahan et al.(2006) apontam que discordar das normas culturais associadas ao padrão corporal nem sempre será suficiente para se estar imune a seus efeitos. Os participantes apesar de apresentarem 
- discurso virtuoso da saúde, da busca do pelo corpo saudável se valem de estratégias para mudança corporal mesmo quando envolve os riscos de procedimentos cirúrgicos com fins estéticos ou de medicamentos para emagrecer ou ganhar massa muscular: "Já tomei uma vez um remédio que minha mãe usava, daí eu fiquei três dias sem dormir, aí depois nunca mais eu tomei." (E19-F); “...quero fazer lipo pra tirar a gordura localizada que é difícil de perder com dieta." (E19-F); "Coloquei prótese de silicone."(E5-F).

A construção social deste corpo como um sinônimo de saúde, bem estar, autodisciplina e distinção disseminou-se, principalmente, por meio de um discurso midiático, gerando representações e sentidos coletivos que interferem diretamente nas escolhas feitas pelos sujeitos (Fallon \& Hausenblas, 2005). Entre os participantes desta pesquisa, podese perceber que na busca do corpo idealizado, mesmo quando pautada no discurso da saúde, utilizam práticas que não são saudáveis, mas aceitáveis como meio obter o padrão estético desejável.

\section{CONSIDERAÇÕES FINAIS}

A pesquisa qualitativa é fundamental para captar as nuances que marcam a diversidade de experiências que compõem as vivências relativas ao corpo. Podese observar que os participantes estabelecem com - corpo uma relação estética, visto que os padrões de beleza culturalmente estabelecidos balizam a percepção corporal, porém esta relação estética parece estar subordinada ao discurso da saúde como meio de justificar ou atenuar ações que visam modelar o corpo por meio de dietas, exercícios físicos, procedimentos cirúrgicos, medicações. Deste modo o culto ao corpo, associado, conforme observamos nos relatos dos participantes, à ausência de gordura corporal está embasado em uma condição do 'ser saudável' e não do ser simplesmente 'belo'. As vivências retratam o corpo idealizado e agora nomeado como 'saudável' como um meio para atingir o sucesso, a felicidade, o reconhecimento social exatamente por atender padrões socialmente compartilhados. Entretanto, esta busca torna-se infindável por haver sempre alguma parte corporal a ser modelada. Este cenário propicia o florescimento da insatisfação corporal constante e do sofrimento psíquico, visto que se torna uma busca impossível de ser concretizada e que ultrapassa os limites do que seria desejável para os cuidados corporais.

Apesar de aparentemente associado a um possível culto narcisista à aparência, este movimento de valorização corporal revela questões mais profundas, que se ligam a uma determinada construção e controle do corpo, que não se limita a decisões de como agir, mas sobre quem ser (Giddens, 2002). Ele passa a existir e ter um sentido dentro de um contexto social que o constrói, atribuindo-lhe representações constituídas de acepções, imagens e significados dentro de um universo simbólico.

Aprofundar o conhecimento sobre as vivências de jovens relativos ao corpo pode contribuir para subsidiar intervenções nesse grupo, ampliando significativamente $\bigcirc$ âmbito de atuação dos profissionais na área da saúde. Entretanto, é necessário o desenvolvimento de outros estudos com esse grupo, além da associação desses achados a dados relativos a comportamentos alimentares inadequados visto que a insatisfação corporal pode ser um fator de risco para o desenvolvimento de transtornos alimentares e outros transtornos psicológicos.

\section{CONFLITOS DE INTERESSES:}

Nenhum conflito financeiro, legal ou político envolvendo terceiros (governo, empresas e fundações privadas, etc.) foi declarado para nenhum aspecto do trabalho submetido (incluindo mas não limitandose a subvençães e financiamentos, conselho consultivo, desenho de estudo, preparação de manuscrito, análise estatística, etc).

\section{REFERÊNCIAS}

Alves, D., Pinto, M., Alves, S., Mota, A., \& Leirós, V. (2009). Cultura e Imagem Corporal. Revista Motricidade, 5(1), 1-20. Recuperado de http://www.revistamotricidade. com/arquivo/2009_vol5_n1/v5n1 a02.pdf

Azevedo, A., Suassuna, D., Barros, J., \& Sampaio, J. (2005). A relação corpo-natureza na modernidade. Sociedade e Estado, 20(1), 23-38. Recuperado de http://www. redalyc.org/articulo.oa?id=339930880003 
Barbosa, M. R., Matos, P. M., \& Costa, M. E. (201 1). As Relações de Vinculação e a Imagem Corporal: Exploração de um Modelo. Revista Psicologia: Teoria e Pesquisa, 27(3), 273-282. Recuperado de http://www.scielo.br/scielo.php?pid=S0102$37722011000300002 \&$ script=sci_abstract\&tlng=pt. doi: $10.1590 /$ S0102-37722011000300002

Bailey, S. D., \& Ricciardelli, L. A. (2010). Social comparisons, appearance related comments, contingent self-esteem and their relationships with body dissatisfaction and eating disturbance among women. Eating Behaviors, 11 (2), 107-112. Recuperado de https://www.ncbi. nlm.nih.gov/pubmed/20188294. doi: 10.1016/i. eatbeh.2009.12.001

Bardin, L. (2003). Análise de conteúdo. Lisboa: Edições 70.

Barros, D. D. (2005). Imagem corporal: a descoberta de si mesmo. História, Ciências, Saúde - Manguinhos, 12(2), 547-54. Recuperado de http://www.scielo.br/scielo. php?pid =S0104-59702005000200020\&script $=$ sci_ abstract\&tlng=pt. doi: 10.1590/s0104$\underline{59702005000200020}$

Beck, U., Giddens, A., \& Lash, S. (1997). Modernização reflexiva. São Paulo: Unesp.

Betz, N.E., Mintz, L., \& Speakmon, G. (1994). Gender differences in the accuracy of self-reported weight. Sex Roles, 30(7-8), 543-552. doi:10.1007/ BF01420801

Resolução $n^{\circ}$ 196, de 10 de outubro de 1996. Recuperado de http://bvsms.saude.gov.br/bvs/saudelegis/cns/1996/ res0196_10_10_1996.html

Camargo, B. V., Goetz, E.R., Bousfield, A. B. S., \& Justo, A. M. (2011). Representações sociais do corpo: estética e saúde. Temas em Psicologia, 19(1), 257-268. Recuperado de http://pepsic.bvsalud. org/scielo.php?script=sci_arttext\&pid=S1413389X2011000100021

Dalleya, S. E., Buunk, A. P., \& Umitc, T. (2009). Female body dissatisfaction after exposure to overweight and thin media images: The role of body mass index and neuroticism. Personality and Individual Differences, 47(1), 47-51. Recuperado de http://isiarticles.com/ bundles/Article/pre/pdf/35260.pdf. doi:10.1016/i. paid.2009.01.044

Damasceno, V.O., Vianna, V.R.A., Vianna, J.M., Lacio, M., Lima, J.R.P., \& Novaes, J.S. (2006). Imagem corporal e corpo ideal. Revista Brasileira de Ciência e Movimento 14(2): 81-94. Recuperado de https://portalrevistas.ucb.br/ index.php/RBCM/article/view/691

Dantas, J. B. (201 1). Um ensaio sobre o culto ao corpo na contemporaneidade. Estudos e Pesquisas em Psicologia,
11 (3), 898-912. Recuperado de http://www.epublicacoes.uerj.br/index.php/revispsi/article/ view $/ 8342 / 6137$

Fallon, E. A., \& Hausenblas, H. A. (2005). Media images of the "ideal" female body: can acute exercise moderate their psychological impact?. Body Image, 2(1), 62-73. Recuperado de https://www.ncbi. nlm.nih.gov/pubmed/18089175. doi: 10.1016/i. bodyim.2004.12.001

Feitosa, C. (2004). Alteridade na estética: reflexões sobre feiúra. In Katz, C. S., Kupermann, D., \& Mosé, V. Beleza, feiúra e psicanálise. Rio de Janeiro: Contra Capa Livraria.

Fernandes, A. E. R. (2007). Avaliação da imagem corporal, hábitos de vida e alimentares em crianças e adolescentes de escolas públicas e particulares de Belo Horizonte (Dissertação de mestrado). Faculdade de Medicina, Universidade Federal de Minas Gerais, Belo Horizonte, MG, Brasil. Recuperado de http://www. agencia.fapesp.br/arquivos/dissertacao_ufmg.pdf

Festinger, L., \& Katz, D. A. (1974). Pesquisa na Psicologia Social. Rio de Janeiro: Fundação Getúlio Vargas.

Fontanella, B. J. B., Luchesi, B. M., Saidel, M. G. B., Ricas, J., Turato, E. R., \& Melo, D. G. (2011). Amostragem em pesquisas qualitativas: proposta de procedimentos para constatar saturação teórica. Cadernos de Saúde Pública, 27(2), 389-394. Recuperado de http://www. scielo.br/scielo.php?script=sci_arttext\&pid=S0102$311 \times 2011000200020$. doi: 10.1590/S0102$311 \times 2011000200020$

Fontanella, B. J. B., Ricas, J., \& Turato, E. R. (2008). Amostragem por saturação em pesquisas qualitativas em saúde: contribuições teóricas. Cadernos de Saúde Pública, 24(1), 17-27. Recuperado de http://www. scielo.br/scielo.php?script=sci_arttext\&pid=S0102$311 \times 2008000100003$. doi: 10.1590/S0102$\underline{311 \times 2008000100003}$

Fontes, O. A., Borelli, F. C., Casotti, L. M. (2012). Como Ser Homem e Ser Belo? Um Estudo Exploratório sobre a Relação entre Masculinidade e o Consumo de Beleza. REAd - Revista Eletrônica de Administração, 18(2), 400-432. Recuperado de http://www.scielo.br/scielo. php?pid=S1413-23112012000200005\&script=sci_ abstract\&tlng=pt. doi: $10.1590 /$ S1413$\underline{23112012000200005}$

Giddens, A. (2002). Modernidade e identidade. Rio de Janeiro: Jorge Zahar.

Godoy, A. S. (1995). Pesquisa Qualitativa: tipos fundamentais. Revista de Administração de Empresas, 35(3), 20-29. Recuperado de http://www.scielo.br/scielo.php?script $=$ sci_ 
arttext\&pid $=$ S0034-75901995000300004. doi: 10.1590/S0034-75901995000300004

Goldenberg, M. (2006). O corpo como capital: para compreender a cultura brasileira. Arquivos em Movimento, 2(2), 115-123. Recuperado de https:// revistas.ufri.br/index.php/am/article/view/9083

Instituto Brasileiro de Geografia e Estatística. (2015). Pesquisa Nacional de Saúde 2013 - Ciclos de vida - Brasil e Grandes Regiões. Rio de Janeiro: IBGE - Coordenação de Trabalho e Rendimento. Recuperado de http:// biblioteca.ibge.gov.br/visualizacao/livros/liv94522. pdf

Kelley, C. C., Neufeld, J. M., \& Musher-Eizenman, D. R. (2010). Drive for thinness and drive for muscularity: opposite ends of the continuum or separate constructs?. Body Image, 7(1):74-7. Recuperado de https://www.ncbi. nlm.nih.gov/pubmed/19944659. doi: 10.1016/i. bodyim.2009.09.008

Kirchof, E. R., \& Bonin, I. T. (2013). Representações do feio na literatura infantil contemporânea. Educação \& Realidade, 38(4), 1069-1088. Recuperado de http:// seer.ufrgs.br/index.php/educacaoerealidade/ article/view/38157. doi: 10.1590/\$2175$\underline{62362013000400004}$

Lopes, J. E., Baldasso, J. G., Sousa, M., Chaud, D. A., \& Camargo, M. C. R. (2012). Imagem Corporal de estudantes de uma ONG na cidade de São Paulo. Revista Simbio-Logias, 5(7), 87-98. Recuperado de http://www.ibb.unesp.br/Home/Departamentos/ Educacao/Simbio-Logias/imagem_corporal_ estudantes.pdf

Ludke, M., \& André, M. E. D. A. (1986). Pesquisa em Educação: Abordagens Qualitativas. São Paulo: EPU.

Machado, M. N. M. (2002). Entrevista de Pesquisa: a interação pesquisador/pesquisado. Belo Horizonte: C/Arte.

McKay, J., Mikosza, J., \& Hutchins, B. (2005). "Gentlemen, the lunchbox has landed" Representations of masculinities and men's bodies in the popular media. In Connell, R. W., \& Kimmel, M. (Eds.), Handbook of Studies on Men and Masculinities. Thousand Oaks, CA: Sage.

Minayo, M.C S. (1996). Ciência, técnica e arte: o desafio da pesquisa social. In Minayo, M. C. S., Pesquisa Social: teoria, método e criatividade. Petrópolis: Vozes.

Minayo, M.C. S. (1998). O desafio do conhecimento: pesquisa qualitativa em saúde ( 5 a ed.). São Paulo: Hucitec.

Miranda, V. P. N., Filgueiras, J. F., Neves, C. M., Teixeira, P. C., \& Ferreira, M. E. C. (2012). Insatisfação corporal em universitários de diferentes áreas de conhecimento. Jornal Brasileiro de Psiquiatria, 61(1),
25-32. Recuperado de http://www.scielo.br/scielo. php?pid =S0047-20852012000100006\&script =sci_ abstract\&tlng=pt. doi: $10.1590 /$ S0047$\underline{20852012000100006}$

Neighborsa, L. A., \& Sobalb, J. (2007). Prevalence and magnitude of body weight and shape dissatisfaction among university students. Eating Behaviors, 8(4), 429-439. Recuperado de https://www.ncbi.nlm. nih.gov/pubmed/17950931. doi: 10.1016/i. eatbeh.2007.03.003

Novaes, J. V., \& Vilhena, J. (2003). De Cinderela a Moura torta: sobre relação a mulher, beleza e feiúra. Interações, 8(15), 9-36. Recuperado de http://pepsic.bvsalud.org/scielo.php? script=sci_ arttext\&pid=S1 413-29072003000100002.

Rech, C.R., Araujo, E.D.S., \& Vanat, J.R. (2010). Auto percepção da imagem corporal em estudantes do curso de educação física. Revista Brasileira de Educação Física e Esporte, 24(2), 285-92. Recuperado de http://www.scielo.br/scielo.php?pid=S180755092010000200011 \&script=sci_abstract\&tlng=pt. doi: $10.1590 /$ S1807-55092010000200011

Pais-Ribeiro, J. L., \& Ribeiro, L. (2003). Estudo de validação de uma escala auto - conceito físico para homens jovens adultos. Revista de Análise Psicológica, 4(21). Recuperado de http://publicacoes.ispa.pt/index.php/ ap/article/view/3. doi: 10.14417/ap.3

Secchi, K., Camargo, B.V., \& Bertoldo, R.B. (2009). Percepção da imagem corporal e representação sociais do corpo. Revista Psicologia: Teoria e Pesquisa, 25(2), 229-236. Recuperado de http://www.scielo.br/scielo. php?pid =S0 102-3772200900020001 1 \&script =sci_ abstract\&tlng=pt. doi: $10.1590 /$ s010237722009000200011

Swinburn, B. A., Sacks, G., Hall, K. D., McPherson, K., Finegood, D.T., Moodie, M. L., \& Gortmaker, S.L. (2011). The global obesity pandemic: shaped by global drivers and local environments. Lancet, 378(9793), 804-14. Recuperado de https://www. ncbi.nlm.nih.gov/pubmed/21872749. doi: 10.1016/ s0140-6736(11)60813-1

Tessmer, C.S., Silva, M.C., Pinho, M.N., Gazalle, F.K., \& Fassa, A.G. (2006). Insatisfação corporal em frequentadores de academia. Revista Brasileira de Ciência e Movimento, 14(1): 7-12. Recuperado de https:// portalrevistas.ucb.br/index.php/RBCM/article/ view/672

Van Den Berg, P., Paxton, S. J., Keery, H., Wall, M., Guo, J., \& Neumark-Sztainer, D. (2007). Body dissatisfaction and body comparison with media images in males and females. Body Image, 4(3), 257-268. Recuperado de 
https://www.ncbi.nlm.nih.gov/pubmed/18089272.

doi: 10.1016/i.bodyim.2007.04.003

Wada, K., Tamakoshi, K., Tsunekawa, T., Otsuka, R., Zhang, H., Murata, C., ... Toyoshima, H. (2005). Validity of self-reported height and weight in a Japanese workplace population. International Journal of Obesity, 29(9), 1093-1099. Recuperado de https://www. ncbi.nlm.nih.gov/pubmed/15925952. doi: $10.1038 /$ si.ijo.0803012

World Health Organization. (1995). Physical Status: the use and interpretation of anthropometry: report of a WHO expert committee. Genebra: Autor. Recuperado de http://apps.who.int/iris/bitstream/10665/37003/1/ WHO_TRS_854.pdf 